\title{
Do FUNDEF ao FUNDEB: O processo político de formulação da Emenda Constitucional no 53/2006
}

From FUNDEF to FUNDEB: the political process of Constitutional Amendment n. 53/2006 formulation

\section{Rosimar de Fátima Oliveira1}

\section{RESUMO:}

O objetivo desse artigo é demonstrar o modo como se deu o processo de elaboração da EC n. ${ }^{\circ}$ 53/2005, descrevendo o seu processo legislativo por meio dos documentos que instruíram as propostas de regulamentação constitucional para os fundos de financiamento da educação no período que compreendeu a promulgação da EC n. ${ }^{\circ}$ 14/1996 e a promulgação da EC n. ${ }^{\circ}$ 53/2005. Serão analisados os documentos publicados no Diário da Câmara dos Deputados entre 1996 e 2006, comênfase no conteúdo das PECs que culminaram no FUNDEB e no seu processo de tramitação, bem como enfatizando o papel desempenhado pelos relatores, pelas comissões especiais e pelo plenário da Câmara dos Deputados nesse percurso legislativo. Verificou-se que as emendas n. ${ }^{\circ}$ 14/1996 e n. ${ }^{\circ}$ 53/2006 formalizam importante veio das reformas educacionais implementadas na educação básica pelos governos Fernando Henrique Cardoso e Luis Inácio Lula da Silva, instituindo a política de fundos não só como recurso de distribuição e controle dos gastos educacionais, mas como recurso de regulação da ação federativa dos entes subnacionais em relação às políticas educacionais.

PALAVRAS-CHAVE: FUNDEF; FUNDEB; financiamento da educação.

\begin{abstract}
:
The aim of this paper is to show how the process of drawing up the CA n. ${ }^{\circ}$ 53/2005 was carried out, describing the legislative process by using documents that instructed the proposed constitutional rules for financing education in the period between the promulgation of the CA n. ${ }^{\circ}$ 14/1996 and the CA n. ${ }^{\circ}$ 53/2005. This review examines the documents published by the House of Representatives' Daily Journal between 1996 and 2006, focusing on the contents of the Constitutional Amendment Proposals that culminated in the FUNDEB and in its procedures, as well as emphasizing the role of rapporteurs, special committees and the House Members plenary in this legislative procedure. The results of the search showed that the amendments $n .^{\circ}$ 14/1996 and n. ${ }^{\circ}$ 53/2006 formalize an important fundament of the educational reforms implemented in basic education by the governments Fernando Henrique Cardoso and Luis Inacio Lula da Silva, establishing the policy of funds not only as resource distribution and control of educational expenses, but as a resource for the regulation of the federal action through subnational entities on education policies.
\end{abstract}

KEYWORDS: FUNDEF; FUNDEB; financing of education. 


\section{Introdução}

A Constituição Federal de 1988 (CF/1988), como lembra Souza (2008), não só é a constituição mais emendada do Brasil, como é também uma das constituições mais emendadas do mundo. Enquanto a CF/1988 apresenta uma taxa de 3,1 emendas ao ano, a taxa de emendamento anual das constituições dos estados norte-americanos, por exemplo, é de 2,54 emendas e a dos países do Leste Europeu de 0,39. Até hoje, com vinte anos de vigência, a CF/1988 recebeu 63 emendas, das quais 57 constitucionais e seis de revisão. Das seis outras constituições que vigoraram no País, a que recebeu o maior número de emendas foi a de 1967 que, com 21 anos de vigência, havia sido emendada 27 vezes. Para Souza (2008, p. 8), uma das razões para esse fato estaria no modelo adotado pelos Constituintes, que optaram pela "constitucionalização dos detalhes das políticas, notadamente as que transformam alguns direitos sociais em políticas". A autora explica, ainda, que a Constituição de 1988 resultou do momento político marcado pelo objetivo de tornar crível e de legitimar 0 novo sistema democrático, dado que foi desenhada antes do fim da transição. Não por acaso, das 62 emendas [atualmente, 63], apenas duas mudaram as regras iniciais aplicáveis ao sistema político. No entanto, 0 desenho das políticas sociais e fiscais caminhou em direção oposta à da estabilidade. Isso porque, em virtude do objetivo legitimador da Constituição, negociações e barganhas referentes às políticas públicas e que encaminhassem alternativas para questões que afetavam as condições sociais da população e o desempenho macroeconômico do país foram marcadas por incertezas quanto a suas possibilidades (SOUZA, 2008, p. 816).

A definição de políticas públicas com tempo de duração delimitado nas disposições transitórias é um exemplo do que menciona Souza (2008), uma vez que impõe avaliação periódica do dispositivo e seu impacto social, tendo em vista sua manutenção ou exclusão do texto constitucional.

A matéria educacional disposta na CF/1988 recebeu quatro emendas desde outubro de 1988, todas emendas constitucionais. A Emenda Constitucional (EC) n. ${ }^{\circ} 11$, de 30 de abril de 1996, altera o art. 207 da CF/1988, permitindo a admissão de professores, técnicos e cientistas estrangeiros pelas universidades brasileiras e concedendo autonomia às instituições de pesquisa científica e tecnológica. A EC n. ${ }^{\circ} 19$, de 04 de junho de 1998, modifica o art. 206, inciso V, da CF/1988, dispondo que o ensino será ministrado com base no princípio da valorização dos profissionais do ensino, garantidos, na forma da lei, planos de carreira para o magistério público, com piso salarial profissional e ingresso exclusivamente por concurso público de provas e títulos.

A EC n. ${ }^{\circ} 14$ e a EC n. 53 são, porém, casos mais explícitos de mudanças constitucionais com vistas à institucionalização de políticas públicas educacionais dispostas em caráter transitório, com forte apelo ao emendamento constitucional. A EC n. ${ }^{\circ}$ 14, de 12 de setembro de 1996, foi iniciativa do Governo Fernando Henrique Cardoso, que justificou sua proposta embasado nas críticas à $\mathrm{CF} / 1988$, definida como um obstáculo para a política de desenvolvimento social e econômico do País (OLIVEIRA, 2008). A Emenda altera o art. 60 do ADCT da CF/1988, que previa utilização dos recursos constitucionais dos poderes públicos para erradicação do analfabetismo e universalização do ensino fundamental, num prazo de dez anos de vigência da CF/1988, e cria o Fundo de Manutenção e Desenvolvimento do Ensino Fundamental e de Valorização do Magistério (FUNDEF), também com um prazo de vigência previsto para dez anos.

A EC n. ${ }^{\circ}$ 53, de 19 de dezembro de 2006, cria - Fundo de Manutenção e Desenvolvimento da Educação Básica eValorização dos Profissionais da Educação(FUNDEB), que vem dar continuidade ao FUNDEF, ampliando seus recursos e mecanismos, uma vez que o FUNDEF teve seu prazo de vigência expirado em 2006. A Emenda modifica também o art. 60 do ADCT, estabelecendo mecanismos para o funcionamento do FUNDEB. Sua proposição e percurso legislativo representam estágios de um mesmo movimento em relação ao financiamento da educação básica, de subvinculação de recursos constitucionais e estabelecimento de maior controle sobre a utilização desses recursos. Como demonstraremos na seção seguinte, o percurso legislativo que vai do FUNDEF até o FUNDEB, articulado por meio das PECs que propuseram aperfeiçoar os mecanismos dessa política de financiamento, confirma a hipótese de que o modo como os dispositivos constitucionais 
regulamentaram as políticas públicas no período pós-1988 constituiu-se num forte mecanismo de incentivo à mudança constitucional.

Considerando essa hipótese, o objetivo deste artigo é demonstrar o modo como se deu o processo de elaboração da EC n. ${ }^{0}$ 53/2005, descrevendo o seu processo legislativo por meio dos documentos que instruíram as propostas de regulamentação constitucional para os fundos de financiamento da educação no período que compreendeu a promulgação da EC n. ${ }^{\circ}$ 14/1996 e a promulgação da EC n. ${ }^{\circ}$ 53/2005. Serão analisados os documentos publicados no Diário da Câmara dos Deputados entre 1996 e 2006 (BARDIN, 2002), com ênfase no conteúdo das PECs que culminaram no FUNDEB e no seu processo de tramitação, bem como enfatizando o papel desempenhado pelos relatores, pelas comissões especiais (CESP) e pelo plenário da Câmara dos Deputados nesse percurso legislativo.

\section{Do FUNDEF ao FUNDEB: percursos legislativos}

A proposição de um fundo para o financiamento da educação básica foi feita ainda durante a tramitação da PEC 233/1995, que criou o FUNDEF, pelo Deputado Pedro Wilson (PT-GO). O Deputado propôs emenda ao texto da PEC 233/1995, restabelecendo o conteúdo do art. $60 \mathrm{ADCT}$ da CF/1988 e criando, no âmbito de cada unidade da federação, o "Fundo de Desenvolvimento da Educação Básica e de Valorização do Magistério". Mediante voto em separado ao substitutivo do Relator JoséJorge (PFL-PE), naComissão Especial, os deputados Ivan Valente (PT-SP), Esther Grossi (PT-RS) e Pedro Wilson (PT-GO) apresentaram também proposta de criação de "Fundos de Desenvolvimento da Educação Básica Pública e Valorização dos Profissionais da Educação", que deveriam ser geridos por representantes dos poderes Executivo, Legislativo e da sociedade civil. Do mesmo modo, os Senadores José Bianco (PT-SE) e José Eduardo Dutra (PT-SE) propuseram, durante a tramitação da PEC 30/1996 no Senado Federal, a substituição do FUNDEF por um fundo que abarcasse toda educação básica. Coerente com seu posicionamento durante a tramitação da PEC 233/1995 na Câmara dos Deputados, o PT votou em bloco contra a aprovação do FUNDEF: foram 46 votos contrários desse partido no primeiro turno de votação e 45 no segundo turno, que teve uma abstenção. No Senado Federal, entretanto, o PT votou favoravelmente à PEC 30/1996, que foi aprovada, ao final, por unanimidade pelos senadores (OLIVEIRA, 2008).

As propostas de criação de um fundo para o financiamento da educação básica, apresentadas pelo PT durante a tramitação da PEC 233/1995, foram reunidas, posteriormente, na PEC 112/1999, de autoria do Deputado Padre Roque (PT-PR). ${ }^{2}$ Além de ampliar a destinação orçamentária da União para manutenção e desenvolvimento do ensino de 18\% para 20\%, a PEC 112/1999 propunha a criação de fundos estaduais para manutenção e desenvolvimento da educação básica pública e de valorização dos profissionais da educação, composto pela totalidade dos recursos constitucionais destinados à educação. O fundo proposto, com vigência prevista para dez anos, modificaria o art. 211 da CF/1988, instituindo-se, portanto, como dispositivo permanente, diferentemente do caráter transitório do FUNDEF, criado pelo art. 60 do ADCT. A PEC 122/1999 encontra-se hoje ainda em tramitação, apensada à PEC 78/1995, de autoria do Deputado Leonel Pavan (PDT-SC), que propõe a ampliação dos recursos constitucionais da União para manutenção e desenvolvimento do ensino de $18 \%$ para $25 \%$ da receita resultante de impostos. A última ação no seu processo de tramitação ocorreu em 06 de março de 2007, encontrando-se, na data de finalização deste artigo, no aguardo da criação de comissão temporária para apreciação da matéria (CÂMARA DOS DEPUTADOS, 1999).

O FUNDEB, porém, tal como instituído pela Emenda Constitucional n. ${ }^{\circ}$ 53, foi resultante do processo legislativo iniciado pela PEC 536/1997, de autoria do Deputado Valdemar Costa Neto (PL-SP). Sua proposta visava garantir a complementação da 
União nos estados onde o valor por aluno ao ano não atingisse o mínimo definido nacionalmente, garantindo também a manutenção do valor por aluno praticado pelos estados e municípios no ano de 1997, anterior ao de criação obrigatória do FUNDEF. Na sua justificativa, o Deputado Valdemar Costa Neto (PL-SP) revela preocupação com o impacto do FUNDEF nas finanças dos municípios e estados, que corrobora um dos aspectos mais contundentes dos debates que sucederam a criação do FUNDEF. Segundo ele, "o Fundo criado pela Emenda n. ${ }^{\circ} 14$ causa estragos (...) às finanças de muitos Municípios. Não se pode dizer que estes municípios eram negligentes quanto ao seu papel na Educação, definido constitucionalmente. Nada há de mais falso" (CÂMARA DOS DEPUTADOS, 2001, p. 2).

A PEC 312/2000, do Deputado Betinho Rosado (PFL-RN), primeira a ser apensada à PEC 536/1997, também apresenta proposta para disciplinar a complementação da União nos casos em que o mínimo nacional não for atingido em cada região político-administrativa brasileira, com a finalidade de reduzir os desequilíbrios regionais e promover equalização das oportunidades educacionais, sobretudo tendo em vista as regiões Norte, Nordeste e Centro-Oeste.

As PECs 536/1997 e 312/2000 chegaram a receber parecer pela inadmissibilidade na Comissão de Constituição, Justiça e Cidadania (CCJC), mediante o Parecer do Deputado José Roberto Batochio (PDT-SP), segundo o qual as propostas não se adequariam ao caráter transitório dos dispositivos constitucionais que propunham modificar - o art. 60 do ADCT - e, por essa razão, não poderiam ser admitidas na forma como se apresentavam (CÂMARA DOS DEPUTADOS, 2001). O parecer, entretanto, não chegou a ser votadonaCCJC, uma vez que as proposições foram arquivadas pelo fim da legislatura, reingressando na legislatura seguinte na Câmara dos Deputados com a designação de um novo relator na CCJC, o Deputado Vilmar Rocha (PFL-GO), que modifica o parecer anterior do Deputado José Roberto
Batochio (PDT-SP). O novo parecer conclui pela admissibilidade das PECs, atendo-se aos aspectos mais formalistas do Regimento Interno da Câmara dos Deputados, tais como os apoiamentos e o respeito às cláusulas constitucionais pétreas (CÂMARA DOS DEPUTADOS, 2003). Um terceiro parecer foi proferido ainda na CCJC, pelo mesmo Deputado Vilmar Rocha (PFL-GO), que apreciou a admissiblidade de outras propostas que foram apensadas à PEC 536/1997, por tratarem de assuntos análogos ou conexos. Foram elas a PEC 415/2001, do Deputado Inácio Arruda (PCdoBCE), a PEC 190/2003, da Deputada Raquel Teixeira (PSDB-GO), a PEC 216/2003, do Deputado Carlos Abicalil (PT-MT), a PEC 105/2003, da Deputada Janete Capiberibe (PSB-AP), a PEC 247/2004, do Deputado Valdemar Costa Neto (PL-SP) e a PEC 415/2005, do Poder Executivo, todas com parecer pela admissibilidade no Relatório do Deputado Vilmar Rocha (PFL-GO). ${ }^{3}$

A PEC 190/2003, tal como a PEC 78/1995, do Deputado Leonel Pavan (PDT-SC), também propõe elevação dos percentuais constitucionais praticados pela União para manutenção e desenvolvimento do ensino de $18 \%$ para $25 \%$. Além disso, propõe introdução do FUNDEF nas disposições constitucionais permanentes e a criação de fundos específicos para a educação infantil e para o ensino médio, respectivamente no âmbito de cada estado e município, subvinculando $30 \%$ dos recursos constitucionais destinados em cada ente federado para a educação.

A PEC 216/2003, do Deputado Carlos Abicalil (PT-MT), propõe modificação no artigo 206 da $\mathrm{CF} / 1988$, criando o "Piso Salarial Profissional Nacional". O piso seria um valor mínimo abaixo do qual nenhum salário poderia ser fixado para os trabalhadores em regime de tempo integral. A criação do piso salarial profissional e a respectiva elevação salarial, segundo o autor, antecipariam uma das metas a ser atingida pelo FUNDEB, a ser criado posteriormente pelo Governo Lula através de proposta de emenda à constituição (CÂMARA DOS DEPTUADOS, 2003, p. 5). A PEC 247/2004, 
do Deputado Valdemar Costa Neto (PL-SP), dispõe também sobre o piso salarial profissional, propondo a unificação do piso em todo território nacional. O autor justifica a PEC vinculando a remuneração do magistério à qualidade da educação e afirma que a "melhoria da qualidade do ensino (...) somente poderá ser alcançada com a valorização do magistério, visto que os docentes exercem um papel decisivo no processo educacional" (CÂMARA DOS DEPUTADOS, 2004, p.2).

A criação do Fundo Nacional da Educação Infantil (FUNAEI) foi proposta pela PEC 105/2003, da Deputada Janete Capiberibe (PSB-AP), com a finalidade de financiar a educação das crianças de zero a três anos. A autora aponta os limites trazidos pelo FUNDEF para a manutenção e expansão das redes municipais de educação infantil, particularmente para as creches, justificando a necessidade de um esforço específico para o atendimento dessa faixa etária. O FUNAEI seria constituído por uma percentagem da receita bruta do Imposto sobre a Renda (IR) e por outra que incide na arrecadação da contribuição social que alimenta o Fundo de Amparo ao Trabalhador (FAT), cuja soma fosse suficiente não para a manutenção, mas para a complementação do financiamento das creches nos Municípios (CÂMARA DOS DEPUTADOS, 2003). A PEC 415/2001 também aborda a educação infantil, subvinculando pelo menos $30 \%$ dos recursos constitucionais destinados à educação nos estados, DF, municípios e União para a manutenção e desenvolvimento da educação infantil. A justificativa do autor corrobora os argumentos apresentados na apresentação da PEC 536/1997 sobre o desprestígio da educação infantil nas políticas de financiamento da educação instituídas a partir do FUNDEF. Segundo ele, "por não serem consideradas as matrículas na educação infantil para efeito da distribuição de recursos [do FUNDEF], este nível de ensino vem sofrendo um crescente enfraquecimento, uma vez que muitos municípios estão congelando as matrículas e não abrindo novas vagas" nesse nível de ensino (CÂMARA DOS DEPUTADOS, 2001, p. 43893).
A PEC 415/2005, apresentada pelo Poder Executivo à Câmara dos Deputados em 16 de junho de 2005, propõe a criação do FUNDEB em substituição ao FUNDEF, modificando o art. 60 do ADCT da CF/1988. A proposição ocorre tardiamente em relação às expectativas geradas pelos compromissos firmados ainda em campanha eleitoral pelo então Presidente Luis Inácio Lula da Silva. Segundo o Deputado Carlos Abicalil (PT-MT), o FUNDEB foi um "compromisso programático do Governo Lula, que deverá ser configurado numa proposta de Emenda à Constituição que se seguirá à reforma tributária" (CÂMARA DOS DEPTUADOS, 2003, p. 5). A proposta de criação de um fundo para a educação básica, contudo, afirma idéia defendida pelo PT desde a formulação do FUNDEF, e mantida no teor das propostas de emenda à Constituição apresentadas posteriormente à aprovação da Emenda Constitucional n. ${ }^{\circ}$ 14/1996. A coerência do PT em relação a tais ideias pode ser confirmada pelo processo legislativo demonstrado acima, exceto pelo tratamento conferido à educação infantil, já que a PEC 415/2005 exclui a creche da cobertura do FUNDEB, deixando fora dos mecanismos de distribuição de recursos previstos nesse Fundo as crianças compreendidas na faixa etária de zero a três anos. ${ }^{4}$

Na Exposição de Motivos que acompanha a PEC 415/2005, o Governo Federal define o FUNDEF como "uma política positiva, porém, segmentada e incompleta". A avaliação se deve ao fato de que o FUNDEF não inclui o ensino médio, a educação de jovens e adultos e a educação infantil nos seus mecanismos de distribuição de recursos. O documento refere-se a um descompasso entre os três níveis de ensino que compõem a educação básica, gerado pela "ausência de uma política que promova a universalização indistinta do atendimento, sustentada por mecanismos que assegurem a melhoria qualitativa do ensino oferecido, com valorização dos profissionais da educação" (CÂMARA DOS DEPUTADOS, 2005, p.28894). Em síntese, a Exposição de Motivos corrobora os argumentos da maioria dos atores 
políticos envolvidos com a implementação e análise do FUNDEF, ratificando as críticas e apresentando soluções que representam boa parte dos acordos já estabelecidos até aquele momento de vigência do FUNDEF. É o caso da complementação da União ao FUNDEF, por exemplo, em torno da qual reuniu-se um forte clamor pela ampliação da sua participação, inclusive com definição a priori dos recursos disponíveis para essa finalidade. ${ }^{5}$

Oforte consenso em torno da proposta de criação do FUNDEB indica, ao que parece, o sucesso da implementação do FUNDEF, proposto pelo Governo Fernando Henrique Cardoso. A oposição a esse Governo, como afirma Melo (2005), em vez de atuar como ponto de veto à reforma, atuou como atores pró-reforma, pressionando para o aprimoramento do seu processo de implementação. O FUNDEF possibilitou "muitas mudanças (...) a um baixo custo para o Executivo, o qual conseguiu revolucionar a estrutura de incentivos dos prefeitos e governadores na área educacional" (MELO, 2005, p. 880). A combinação desses fatores explica a solução de continuidade adotada pelo Governo do PT com a proposição da PEC 415/2005.

A apresentação da PEC 415/2005 acelerou o processo legislativo do conjunto de propostas que tramitavam apensadas à PEC 536/1997. Se entre a apresentação desta proposta, em 1997, até a apresentação da proposta do Poder Executivo passaram-se cerca de oito anos, o equivalente a duas legislaturas, o tempo decorrido da apresentação da PEC 415/2005 até sua aprovação foi de cerca de dezoito meses. Esse dado confirma a tese que enuncia a precedência do Executivo sobre o Legislativo na aprovação de matérias sobre educação. Segundo OLIVEIRA (2009),

não só o Poder Executivo obtém maior aproveitamento em relação às suas propostas apresentadas [ao Legislativo], como, também, o Legislativo não demonstrou aproveitamento em relação às próprias propostas. Assim, no interior do Parlamento há um vácuo legislativo no que se refere ao poder de legislar sobre matérias educacionais, não obstante o volume de proposições apresentadas (OLIVEIRA, 2009, p. 66-7).
Nas disposições permanentes da CF/1988, a PEC 415/2005 propõe modificar apenas o $\S 5^{\circ}$ do art. 212, definindo que a contribuição social do salário-educação passa a constituir fonte adicional para a educação básica pública. As demais propostas de modificação referem-se ao art. 60 do ADCT. O núcleo da PEC está na criação do FUNDEB, com vigência prevista até 31 de dezembro de 2009, composto por recursos dos estados, DF e municípios, que chegariam a $20 \%$ do total de impostos previstos a partir do terceiro ano de vigência do fundo. Nos estados onde o mínimo nacional por aluno não fosse atingido, a União complementaria os recursos do fundo destinando, para essa finalidade, o montante de 4,3 bilhões de reais a partir do quarto ano de vigência do fundo, respeitando o limite de $30 \%$ dos seus recursos constitucionais para a educação. Além disso, a complementação da União seria realizada mediante redução permanente de outras despesas, inclusive despesas de custeio. Ao pagamento dos profissionais do magistério da educação básica em efetivo exercício reservou-se o percentual de $60 \%$ dos recursos do FUNDEB, como ocorria em relação ao mecanismo de remuneração dos professores instituído pelo FUNDEF. A distribuição dos recursos consideraria a totalidade dos alunos matriculados no ensino fundamental no primeiro ano de vigência do fundo e, para a pré-escola, ensino médio e educação de jovens e adultos consideraria um quarto das matrículas no primeiro ano, metade das matrículas no segundo ano, três quartos no terceiro e a totalidade das matrículas a partir do quarto ano (CÂMARA DOS DEPUTADOS, 2005).

A partir da apresentação da PEC 415/2005, todo o curso do processo legislativo passou a ser orientado por esta proposta. A apreciação da matéria na CESP teve como Relatora a Deputada lara Bernardi (PT-SP), que apreciou, no seu relatório, além do conjunto de propostas apensadas, as 35 emendas apresentadas na CESP. O relatório acatou a proposta de incluir na distribuição de recursos do FUNDEB as crianças de zero a três anos, atendidas em creches. A relatora incluiu, 
também, na versão do seu texto que apresentou à CESP, proposta de criação de um piso salarial nacional, além de ampliar a contribuição da União de 4,3 bilhões para 4,5 bilhões de reais a partir do quarto ano de vigência do FUNDEB e antecipar a contribuição nos primeiros anos na seguinte proporção: 2 bilhões no primeiro ano, 2,85 bilhões no segundo ano, 3,7 bilhões no terceiro ano.

O Deputado Gastão Vieira (PMDB-MA) apresentou voto em separado ao Substitutivo da Relatora, opondo-se aos aspectos substanciais apresentados pela Deputada lara Bernardi (PT-SP). Propõe excluir o piso salarial nacional, justificando que sua criação comprometeria financeiramente os estados mais pobres. Alem disso, segundo ele, a PEC deveria "dizer claramente que só poderão ser matriculados no ensino fundamental alunos com idade de 6 a 15 anos no máximo. E, no ensino médio, alunos entre 14 e 18 anos. Isso evitará a inflação de matrículas nessas modalidades do ensino, o que pode diluir ainda mais o valor per capita destinado a cada nível de ensino" (CÂMARA DOS DEPUTADOS, 2005, p. 2).

A Deputada lara Bernardi (PT-SP), após as discussões suscitadas pela primeira versão de seu relatório, apresentou complementação de voto com uma segunda versão de Substitutivo. Além dos entendimentos mantidos no interior do Parlamento, a relatora promoveu negociações com o Poder Executivo. Segundo ela,

por solicitação de alguns Parlamentares da Comissão Especial, de diferentes partidos, da base do governo e da oposição, participamos de mais um esforço de negociação junto ao Ministério da Educação (...). Deste debate resultaram as alterações (...) que julgamos oportunas para o aperfeiçoamento de nosso Substitutivo (CÂMARA DOS DEPUTADOS, 2005, p. 3)

OSubstitutivo com as modificações introduzidas pela Relatora foi aprovado por unanimidade na CESP em 08 de dezembro de 2005. No Plenário da Câmara dos Deputados, no primeiro turno, o Substitutivo foi aprovado com 457 votos "sim" e 5 "não", ressalvados os destaques. No segundo turno, o Substitutivo foi aprovado com 399 votos "sim", dois "não" e duas abstenções.

Aprovadona Câmara dos Deputados, a matéria passou a apreciação do Senado Federal, que introduziu na PEC um conjunto de modificações de caráter pontual, dentre as quais se destacam: a valorização e o piso salarial nacional apenas para os profissionais da educação escolar pública; definição da faixa de zero a cinco anos de idade para a educação infantil; determinação de que os recursos municipais sejam sempre aplicados no ensino fundamental e na educação infantil e os recursos estaduais no ensino fundamental e médio; proposição do PIS/PASEP como fonte de financiamento para a qualificação e a educação profissional do trabalhador e seus dependentes e definição da destinação exclusiva dos recursos do FUNDEB para a educação presencial (CÂMARA DOS DEPUTADOS, 2006).

A Deputada lara Bernardi (PT-SP) foi novamente designada como relatora na CESP destinada a proferir parecer ao Substitutivo encaminhado pelo Senado, bem como às quatro emendas encaminhadas ao referido Substitutivo. O parecer da Relatora foi favorável à maioria das modificações introduzidas pelo Senado. Contrapõe-se somente à proposição de utilização do PIS/PASEP como fonte adicional de recursos para o FUNDEB e à determinação de utilização dos recursos municipais e estaduais exclusivamente nos níveis de ensino sob as respectivas responsabilidades. Aprovado por unanimidade na CESP, o Substitutivo foi encaminhado ao plenário da Câmara dos Deputados, onde foi aprovado no primeiro turno com 346 votos "sim", cinco "não" e uma abstenção. No segundo turno votaram 333 parlamentares, dos quais 328 "sim" e 5 "não". A Emenda Constitucional n. 53 foi promulgada em 19 de dezembro de 2006 (CÂMARA DOS DEPUTADOS, 2006).

\section{As políticas educacionais entre o FUNDEF e O FUNDEB}

A tendência de constitucionalização das políticas públicas verificada na CF/1988 foi uma das razões que levou a que sua vigência, nos últimos vinte anos, tenha sido marcada por uma taxa de emendamento anual considerada alta. No caso das disposições constitucionais sobre a educação, o fato de 0 art. 60 do ADCT ter definido critérios de utilização dos recursos para a manutenção e o desenvolvimento do ensino pelos poderes públicos deu centralidade a esse dispositivo, levando a que duas das principais 
emendas constitucionais promulgadas no período pós-1988 - a EC n. ${ }^{\circ}$ 14/1996 e a EC n. ${ }^{\circ}$ 53/2006 - tenham como objetivo modificar esse dispositivo. As emendas formalizam importante veio das reformas educacionais implementadas na educação básica pelos governos Fernando Henrique Cardoso e Luis Inácio Lula da Silva, instituindo a política de fundos não só como recurso de distribuição e controle dos gastos educacionais, mas como recurso de regulação da ação federativa dos entes subnacionais em relação às políticas educacionais.

O FUNDEB ratifica os princípios constitucionais instituídos pelo FUNDEF, ampliando sua cobertura e a concepção de direito à educação implícita nessa política. O amplo apoio à criação do FUNDEB recebido dos parlamentares de partidos políticos situados em todos os espectros ideológicos revela uma avaliação positiva do FUNDEF quanto a um conjunto significativo de seus resultados para o ensino fundamental, em particular, e para a educação brasileira, no geral, mesmo que ocultada por críticas pontuais e esporádicas. O caráter relativamente consensual do FUNDEB demonstra, ao que parece, uma ausência completa de alternativa ao projeto político de financiamento da educação em curso. Se, por um lado, o FUNDEB se fortalece em razão disso, por outro, parece incomodamente confirmar o quanto os partidos políticos no Brasil, pelo menos no que se refere à educação, não se diferenciam do ponto de vista programático (GRACINDO, 1994).

\section{Referências}

ABREU, M. Estudo sobre as possibilidades de continuidade do FUNDEF e o financiamento da educação básica no País. Série Estudo. Brasília: Câmara dos Deputados, Consultoria Legislativa, mai. 2003, 13 p.

BARDIN, L. Análise de conteúdo. Lisboa: Edições 70, 2002.

CALLEGARI, C. Financiamento da educação básica pública: o FUNDEB em substituição ao FUNDEF alguns elementos para discussão. Brasília, 2004, mimeo.

CÂMARA DOS DEPUTADOS. Comissão especial destinada a proferir parecer à Proposta de Emenda Constitucional n. ${ }^{\circ}$ 536-A, de 1997. Complementação de Voto da Relatora lara Bernardi. Avulso. Brasília: Câmara dos Deputados, 08/dez.2005, $12 \mathrm{p}$.

CÂMARA DOS DEPUTADOS. Parecer ao Substitutivo do Senado Federal à PEC 536/1996. Diário da Câmara dos Deputados. Brasília: Câmara dos Deputados, 10/nov./2006, p. 50092-96.

CÂMARA DOS DEPUTADOS. Parecer do Deputado José Roberto Batochio pela inadmissibilidade da PEC 536/1997 e 312/2000. Avulso. Brasília: Câmara dos Deputados, 03/ago./2001, 14 p.

CÂMARA DOS DEPUTADOS. Parecer do Deputado Vilmar Rocha pela admissibilidade da PEC 536/1997 e 312/2000. Avulso. Brasília: Câmara dos Deputados, 31/jul./2003, 4 p.

CÂMARA DOS DEPUTADOS. Proposta de Emenda à Constituição n. ${ }^{\circ}$ 105, de 25 de junho de 2003. Avulso. Brasília: Câmara dos Deputados, 25/jun./2003, 7 p.

CÂMARA DOS DEPUTADOS. Proposta de Emenda à Constituição n. ${ }^{0}$ 216, de 10 de dezembro de 2003. Avulso. Brasília: Câmara dos Deputados, 10/dez./2003, 7 p.

CÂMARA DOS DEPUTADOS. Proposta de Emenda à Constituição n. ${ }^{\circ}$ 247, de 11 de março de 2004. Avulso. Brasília: Câmara dos Deputados, 11/mar./2004, 3 p.

CÂMARA DOS DEPUTADOS. Proposta de Emenda à Constituição n. ${ }^{\circ}$ 415, de 05 de setembro de 2001. Diário da Câmara dos Deputados. Brasília: Câmara dos Deputados, 19/set./2001, p. 43892-898.

CÂMARA DOS DEPUTADOS. Proposta de Emenda à Constituição n. ${ }^{\circ} 415$, de 16 de junho de 2005. Mensagem n. ${ }^{\circ}$ 352/2005. Aviso n. ${ }^{\circ}$ 572/2005 da Casa Civil. Diário da Câmara dos Deputados. Brasília: Câmara dos Deputados, 28/jun./2005, p. 28892-898.

CÂMARA DOS DEPUTADOS. Proposta de Emenda à Constituição n. ${ }^{\circ} 415$, de 16 de junho de 2005. Avulso. Brasília: Câmara dos Deputados, 16/jun./2005, 10 p.

CÂMARA DOS DEPUTADOS. Proposta de Emenda à Constituição n. ${ }^{\circ}$ 536, de 14 de outubro de 1997. Diário da Câmara dos Deputados. Brasília: Câmara dos Deputados, 19/out./1999, p. 49361-362.

CÂMARA DOS DEPUTADOS. Redação do Substitutivo à Proposta de Emenda Constitucional 536, de 1997, para 
o segundo turno de discussão. Diário da Câmara dos Deputados.Brasília: Câmara dos Deputados, 26/jan./2006, p. 4593-97.

CÂMARA DOS DEPUTADOS. Substitutivo do Senado à Proposta de Emenda à Constituição n. ${ }^{\circ}$ 9, de 2006. Avulso. Brasilia: Câmara dos Deputados, 05/jul./2006, 3 p.

CÂMARA DOS DEPUTADOS. Voto em separado do Deputado Gastão Vieira ao Relatório apresentado à PEC 536-A, de 1997. Avulso. Brasília: Câmara dos Deputados, 07/dez./2005, 2p.

GRACINDO, R. V. O escrito, o dito e o feito: educação e partidos políticos. Campinas: Papirus, 1994.

MACHADO, M. G. F. A proposta de FUNDEB do Executivo Federal: interlocuções na formulação da proposta. Porto Alegre: UFRGS, 2007 (dissertação de mestrado).

MELO, M. A. O sucesso inesperado das reformas de segunda geração: federalismo, reformas constitucionais e política social. DADOS - Revista de Ciências Sociais. RJ: IUPERJ, vol. 48, n. ${ }^{\circ}$ 4, 2005, p. 845 a 889.

OLIVEIRA, R. de F. Polf́ticas educacionais no Brasil: qual o papel do Poder Legislativo? Curitiba: Protexto, 2008.

OLIVEIRA, R. de F. O FUNDEF em três dimensões: formulação, regulamentação e implementação. RJ: Publit, 2008.

PINTO J. M. R. Requisitos para a construção do Fundeb. In: LIMA, M. J. R.; IDONET, V. (orgs.). FUNDEB: avanços na universalização da educação básica. Brasília: INEP, 2006. p. 89-103.

SOUZA, C. Regras e contexto: as reformas da Constituição de 1988. Dados - Revista de Ciências Sociais. RJ: IUPERJ, vol. 51, n. ${ }^{\circ} 4,2008$, p. 791 a 823.

Recebido em Dezembro de 2008.

Aprovado em Abril de 2009. 